\title{
Aspectos geomorfológicos e pedogenéticos na bacia do riacho Engenho Velho, município de Pitimbu-PB
}

\author{
Analysis of the geomorphological and pedogenetic aspects in the basin of Engenho Velho \\ river, the city of Pitimbu-PB
}

Santos $^{1}$, J. L.; Vital ${ }^{1}$, S. R. O.

jluizx7@hotmail.com

\begin{abstract}
Resumo
Atualmente, no Brasil, os levantamentos de solos em escalas detalhadas são relativamente escassos. Com o avanço das geotecnologias, a realização de estudos dessa natureza tem se tornado mais viáveis em virtude da disponibilidade de informações cartográficas, tais como imagens de satélites de Modelos Digitais de Elevação. Levando em consideração essa questão, o presente estudo tem o objetivo de analisar os aspectos geomorfológicos e pedogenéticos na bacia do riacho Engenho Velho, situado no município de Pitimbu (PB), por meio de técnicas de análise espacial. Através de técnicas de geoprocessamento foi produzido um Modelo Numérico do Terreno com base em informações extraídas a partir das cartas topográficas, que serviram como base para elaboração dos mapas de hipsometria, declividade e exposição de vertentes, onde foi possível inferir a influência dos fenômenos geomorfológicos na referida área, bem como obter informações que subsidiam planejamentos para trabalho de campo. A aplicação de técnicas de geoprocessamento se mostraram bastante eficazes na manipulação dos dados e obtenção de resultados, sendo possível verificar com mais eficácia, a influência dos atributos topográficos primários.
\end{abstract}

Palavras-chave: Geomorfologia, Pedologia, bacia do Riacho Engenho Velho-Pitimbu/PB.

\begin{abstract}
Currently in Brazil, soil surveys in the detailed scales are relatively scarce. With the advancement of geotechnology, conducting such studies has become more viable because of availability of cartographic information such as images of Digital Models satellite elevation. Considering this issue, the present study aims to analyze the geomorphological and pedogenetic aspects in basin of Engenho Velho river, located in the city of Pitimbu (PB), through spatial analysis techniques. Through geoprocessing techniques was produced a Digital Terrain Model based on information extracted from the topographic maps, which served as the basis for preparation of hypsometry maps, slope and exposure aspects, where it was possible to infer the influence of geomorphological phenomena in said area as well as information that support planning for field work. The application of GIS techniques are quite effective in manipulating the data and getting results, and you can check more effectively the influence of primary topographic attributes.
\end{abstract}

Keywords: Geomorphology, Pedology, basin of Engenho Velho river.

\section{INTRODUÇÃO}

Nas últimas décadas, a forma do desenvolvimento econômico no Brasil resultou na degradação dos recursos naturais através do uso de novas tecnologias voltadas à otimização da produção industrial, porém inadequadas ao uso sustentável dos recursos naturais. A utilização dessas tecnologias no meio agrícola, raramente levaram em consideração o manejo e planejamento correto dos recursos naturais, causando o desgaste contínuo do ambiente físico (FIORIO et al., 2000). 
Nesse contexto, os solos tornam-se um dos elementos mais vulneráveis da paisagem, onde se verifica diversos impactos, tais como: erosão, acidificação, desertificação e salinização.

O uso das geotecnologias pode auxiliar de forma bastante eficaz a realização de estudos pedológicos com base na distinção de paisagens, uma vez que estabelece limites entre as classes de solos a partir de feições identificadas em fotografias aéreas, imagens de satélites, Modelos Digitais de Elevação e outras bases, tornando possível correlacioná-las. Para isso, o entendimento das relações solos-relevo fornece uma melhor compreensão da distribuição das unidades pedológicas, considerando que o relevo influencia na formação e evolução dos solos, regulando o fluxo da água e o tempo de exposição dos materiais (ROSSI; QUEIROZ NETO, 2001; CAMPOS et al., 2006; IPPOLITI et al., 2005; LACERDA et al., 2005; SARMENTO et al., 2008; SILVA et al., 2011).

As geotecnologias vêm sendo cada vez mais utilizadas em função das grandes inovações na área do geoprocessamento, uma vez que torna possível o processamento de informações espaciais e a geração de dados de forma rápida e menos onerosa, quando comparado aos métodos tradicionais de levantamentos pedológicos (CARVALHO JÚNIOR et al., 2003; MENDONÇA-SANTOS; BARROS et al., 2004).

Normalmente, no Brasil, quando se utiliza geotecnologias para estudos dessa natureza, quase sempre se tem a intenção de identificar os tipos de uso do solo e a aptidão agrícola dos mesmos (TEOTIA et al., 2003; SOUSA et al., 2004; MENDOÇA, LOMBARDI NETO e VIÉGAS, 2006; SOUSA et al., 2007; BARBOSA, ANDRADE e ALMEIDA, 2009; NASCIMENTO et al., 2013), porém poucos são voltados exatamente ao estudo dos solos e sua evolução (CALDERANO FILHO et al., 2005; DIAS et al., 2005; BRAGA et al., 2009; CARVALHO et al., 2009; COSTA et al., 2009; COELHO, 2010; SILVEIRA, 2010; SILVA et al., 2011; LACERDA et al., 2015).

Deve-se ressaltar que, estudos voltados aos solos, sobretudo no estado da Paraíba, são relativamente escassos ou praticamente inexistentes (DUARTE et al., 2004; CAMPOS; QUEIROZ, 2006; SOUSA et al., 2007; ANSELMO, 2011; DINIZ, et al., 2013; FRANCISCO, et al., 2015), tornando urgente a execução de pesquisas nessa linha.

No Brasil, os levantamentos de solos se iniciaram nos anos de 1950, após o término da segunda guerra mundial pela FAO/UNESCO. A partir daí surgiu a necessidade de mapear os solos no território nacional brasileiro, uma vez que comporia um mapa de mesmo tema da América do Sul e do mundo. Todavia, esse projeto foi realizado em escalas relativamente pequenas, caracterizando um trabalho apenas exploratório e de reconhecimento. Posteriormente, entre os anos de 1970 e 1985, o projeto Radam Brasil utilizou interpretação de imagens de radar sendo possível a geração de mapas em escala de 1:1.000.000 em todo o território nacional. A Classificação Brasileira de Solos atual foi iniciada em 1979, baseando-se na experiência do Sistema Americano de 1949, 
onde, em 1999, foi divulgada a $1^{\text {a }}$ edição do Sistema de Classificação (JACOMINE, 2009). Contudo, apesar desse sistema ter chegado em sua terceira edição no ano de 2013, ainda existe ainda uma grande necessidade de efetuar levantamentos pedológicos detalhados que sirvam como base para planejamentos das variadas áreas afins, bem como manuais que padronizem os levantamentos pedológicos que já estão sendo desenvolvidos. Outros países como os Estados Unidos, Argentina e África do Sul, por exemplo, possuem boa parte de seu território mapeado detalhadamente (LEPSCH, 2013).

Levando em consideração esse contexto, o presente trabalho tem como objetivo de analisar os aspectos geomorfológicos e pedogenéticos da bacia do riacho Engenho Velho, situado no município de Pitimbu (PB), por meio de técnicas de análise espacial, visando oferecer subsídios para o mapeamento de detalhe dos solos.

\subsection{Localização e caracterização da área em estudo}

A bacia do riacho Engenho Velho possui uma área total de $9,2 \mathrm{~km}^{2}$, estando localizada no município de Pitimbu, na mesorregião da mata paraibana e microrregião do Litoral Sul (Figura 1).

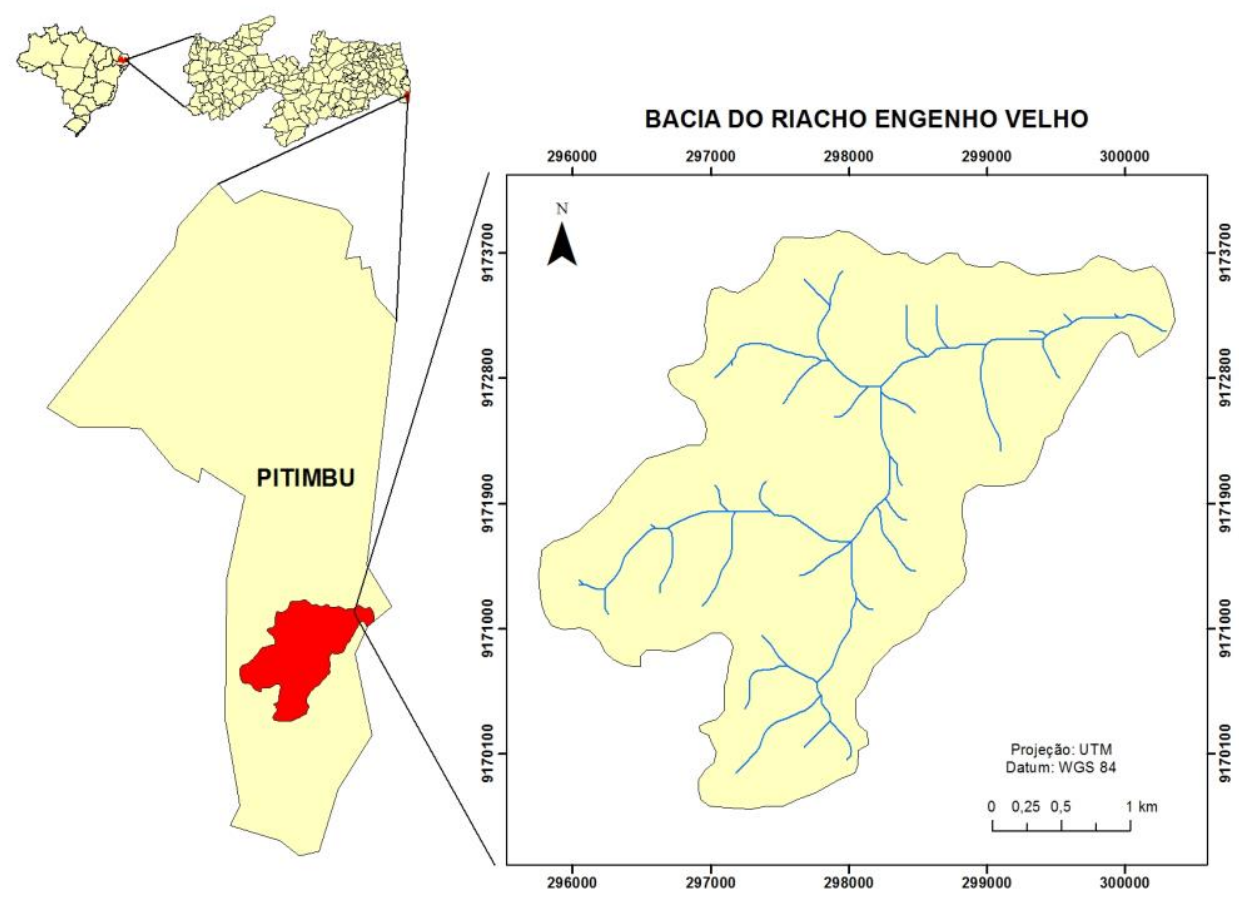

Figura 1. Localização da bacia do riacho Engenho Velho, Pitimbu (PB). 
A mesma constitui uma área predominantemente rural e tem uma economia baseada na produção agrícola familiar, desenvolvida, geralmente, nos assentamentos (MOURA, 2005).

A área de estudo está situada na zona da mata paraibana, onde a vegetação nativa é formada por espécies típicas da Floresta Atlântica, que reúne um variado ecossistema acompanhando as particularidades climáticas e geográficas da região, contudo, a área atual da vegetação nativa representa apenas $5 \%$ do total, devido ao intenso cultivo da cana-de-açúcar, bem como a influência dos demais fatores antrópicos, sobretudo, na área costeira do estado (PEREIRA; ALVES, 2007).

Em relação ao clima, de acordo com Pereira et al. (2012), a normal histórica predominante no litoral da Paraíba chega a $2.145,4 \mathrm{~mm}$. As temperaturas mais altas podem ser verificadas nos períodos de estação seca que se inicia de setembro a fevereiro, chegando a temperatura média de $26^{\circ} \mathrm{C}$, contudo nos meses de dezembro, janeiro e fevereiro a temperatura média pode alcançar até $28^{\circ} \mathrm{C}$.

Em termos geológicos, a mesma se encontra nos domínios da Bacia Sedimentar da Paraíba, sendo limitada, a norte, pela falha de Mamanguape, a qual constitui uma ramificação do Lineamento Patos, e, a sul, pelo Lineamento Pernambuco (BARBOSA; LIMA FILHO, 2005).

A geomorfologia da área de estudo está caracterizada pelos domínios dos baixos planaltos costeiros e baixada litorânea. Os baixos planaltos estão situados na faixa dos tabuleiros litorâneos, constituindo unidades geomorfológicas planas, limitando-se, a leste, pelas falésias geralmente inativas. As baixadas litorâneas são formadas basicamente por sedimentos marinhos, fluviais e flúvio-marinhos, representando um relevo relativamente baixo, na maioria das vezes, inferiores a 10 metros de altitude. Além disso, ocorrem planícies fluviais com cotas altimétricas superiores em locais mais afastados da costa litorânea. São áreas instáveis que sofrem frequentes modificações influenciadas pelos períodos chuvosos, onde se verifica a recorrência processos erosivos, bem como deposição em épocas de estiagem (FURRIER, 2007).

Segundo Beltrão et. al. (2005), a hidrologia da região é formada pelos rios Abiaí, Garaú, Mucatu, Aterro, Papocas, Camocim e Goiana, bem como os riachos Engenho Velho, Andreza, Massapê, João Gomes, Córrego e Arame, e as lagoas do Brandão e Frazão, sendo que, todos os rios, riachos possuem característica perene.

\section{METODOLOGIA}

\subsection{Procedimentos técnicos}

A presente pesquisa utilizou dados altimétricos extraídos de cartas topográficas na escala de 1:10.000, cedidas pelo INTERPA (Instituto de Terras e Planejamento Agrícola do Estado da 
Paraíba). De posse das cartas, foram vetorizadas as curvas de nível, a partir das quais foi construído um MNT (Modelo Numérico do Terreno), que foi utilizado para a elaboração dos mapas de hipsometria, declividade e exposição de vertentes.

A hipsometria foi obtida com base nas curvas de nível do terreno, sendo definidos intervalos com 6 metros de amplitude. As informações de declividade foram geradas a partir de uma operação por vizinhança local, definida por um plano tangente à posição da superfície modelada pelo MNT sobre uma base representada por uma grade triangular (TIN) Triangular Irregular Network.

A exposição das vertentes, também construída a partir do TIN, juntamente com a declividade, consiste na geometria de exposição da superfície do terreno, a qual foi obtida com base no ângulo azimutal.

\section{RESULTADOS E DISCUSSÃO}

\subsection{Declividade}

A partir da análise do mapa de declividade foi possível verificar que existe a predominância da categoria plano (0-3\%) que equivale a aproximadamente 476,65 ha da área total, onde predominam os tabuleiros costeiros. A região onde ocorrem inclinações suave ondulado (3-8\%) e moderadamente ondulado (8-13\%) correspondem aproximadamente 240,39 ha da área, estando situadas, principalmente, entre as regiões de alta e média vertente. As classes com inclinações mais acentuadas, isto é, ondulado (13-20\%), forte ondulado (20-45\%) e escarpado (>45\%) somam 172,74 ha, o que corresponde a $20 \%$ da área total da bacia (Tabela 1).

Tabela 1: Classes de declividade e suas respectivas áreas e percentuais.

\begin{tabular}{l|c|c|c}
\hline \multicolumn{4}{c}{ Classes das declividades e suas respectivas áreas e percentuais } \\
\hline Classes & Intervalos (\%) & Área (ha) & Percentual \\
\hline Plano & $0-3$ & 476,65 & $54 \%$ \\
\hline Suave ondulado & $3-8$ & 121,84 & $14 \%$ \\
\hline $\begin{array}{l}\text { Moderadamente } \\
\text { Ondulado }\end{array}$ & $8-13$ & 118,55 & $13 \%$ \\
\hline Ondulado & $13-20$ & 103,31 & $12 \%$ \\
\hline Forte ondulado & $20-45$ & 59,33 & $7 \%$ \\
\hline Escarpado & $>45$ & 10,10 & $1 \%$ \\
\hline
\end{tabular}

Fonte: Acervo dos autores. 
Através das informações referentes ao grau de inclinação das vertentes, torna-se possível visualizar os principais setores da paisagem, permitindo, assim, uma melhor visualização dos setores de transição entre os diferentes pedons.

$\mathrm{Na}$ bacia, verifica-se que a declividade geral é suave, com ocorrência de poucas parcelas íngremes, basicamente relacionadas aos vales fluviais, onde, certamente há uma grande transição entre diferentes tipos de solos (Figura 2).

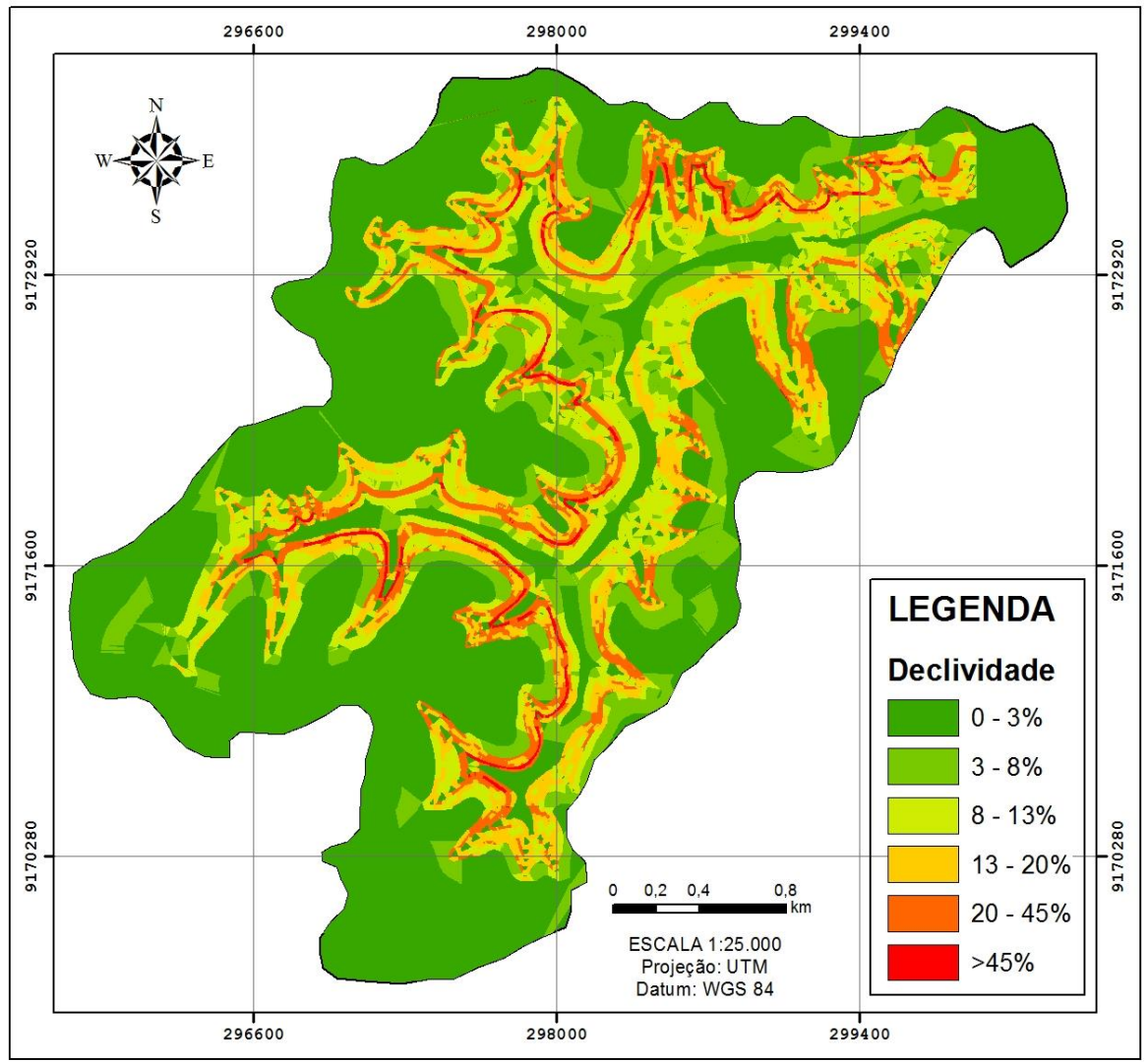

Figura 2. Mapa de declividade da bacia do riacho Engenho Velho, Pitimbu (PB).

\subsection{Hipsometria}

De acordo com a hipsometria, levando em consideração a geologia da área, é possível inferir que a região é caracterizada por leques aluviais pleistocênicos nas cotas entre 5 e 60 metros (Figura 3). 


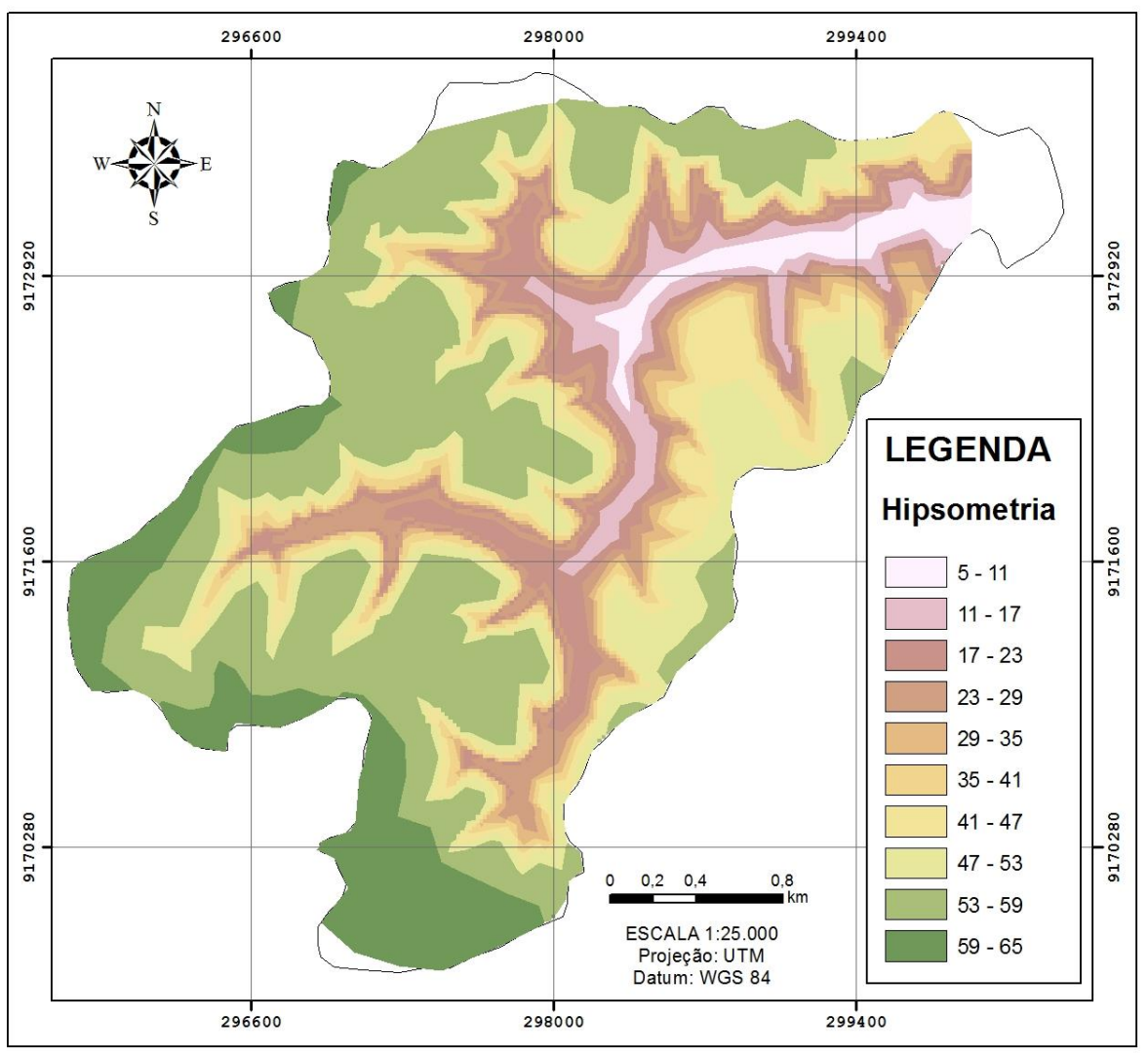

Figura 3. Mapa hipsométrico da bacia do riacho Engenho Velho, Pitimbu (PB).

A análise da curva hipsométrica permitiu inferir alguns aspectos inerentes aos processos pedogenéticos que se desenvolvem na área. É possível acreditar que no topo da vertente, os processos pedogenéticos ocorram de forma mais frequente, caracterizando uma porção do terreno com solos mais desenvolvidos. Por outro lado, nos setores de maior inclinação, os solos podem se mostrar gradativamente menos desenvolvidos. Essa característica é mais expressiva nas cotas entre 20 e 30 metros de altitude, onde nota-se uma concavidade na curva hipsométrica, indicando predominância dos processos morfogenéticos, caracterizando uma elevada susceptibilidade à erosão. Todavia, a obtenção de uma curva predominantemente convexa foi relevante para compreender que existe um predomínio da pedogênese na área, salvo as porções onde a ação antrópica tem alterado a dinâmica natural do ambiente. Além disso, a curva hipsométrica oferece suporte para o mapeamento que será realizado, indicando as áreas que devem ser realizadas as amostragens (Figura 4). 


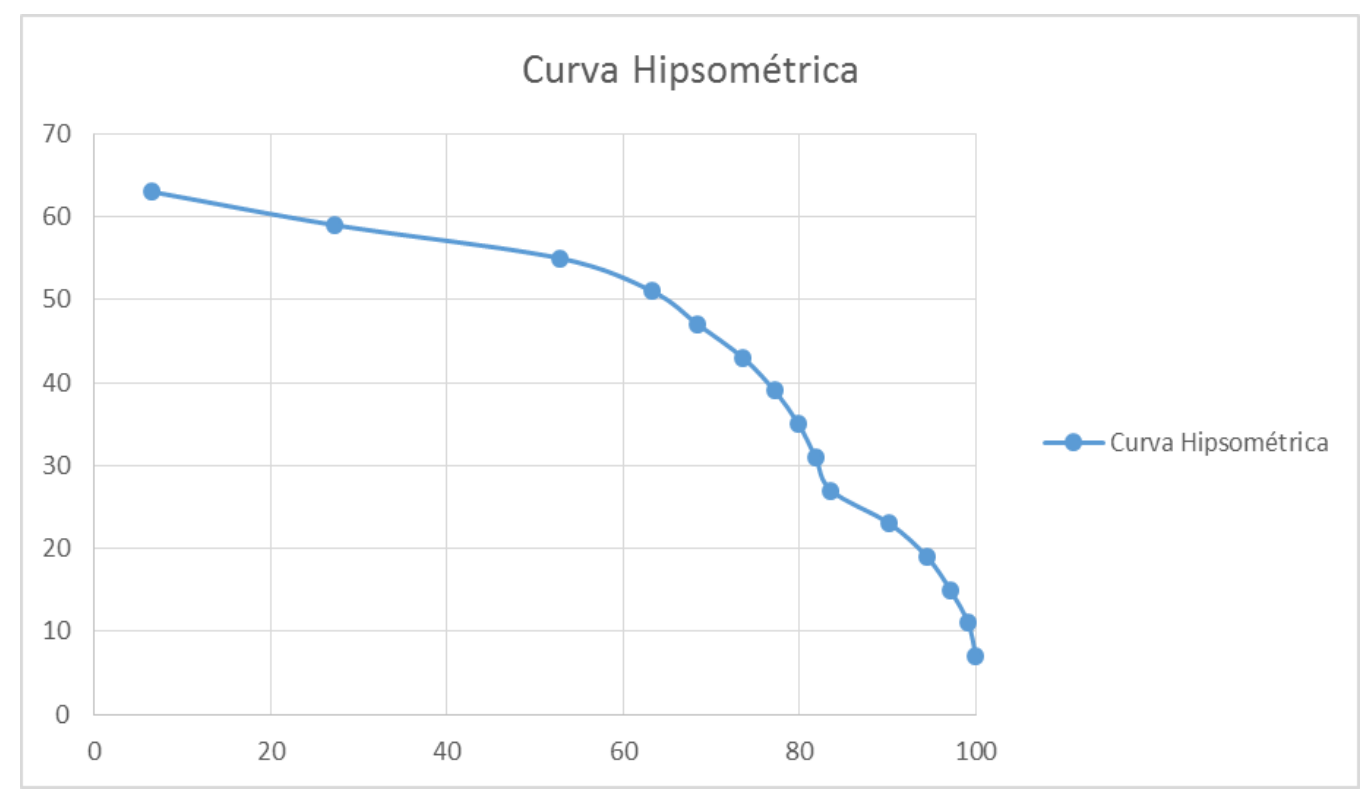

Figura 4. Gráfico com curva hipsométrica da bacia do riacho Engenho Velho, Pitimbu (PB).

\subsection{Exposição das vertentes}

Através do mapa de exposição das vertentes foi possível verificar as orientações das encostas na referida área, bem como a sua influência nos processos morfogenéticos (Figura 5). Em períodos com maiores ocorrências de pluviosidade, onde a ação dos ventos litorâneos é mais veemente, as encostas expostas para o sentido sudeste e leste provavelmente terá maior suscetibilidade de erosão e, portanto, o processo pedogenético será retardado.

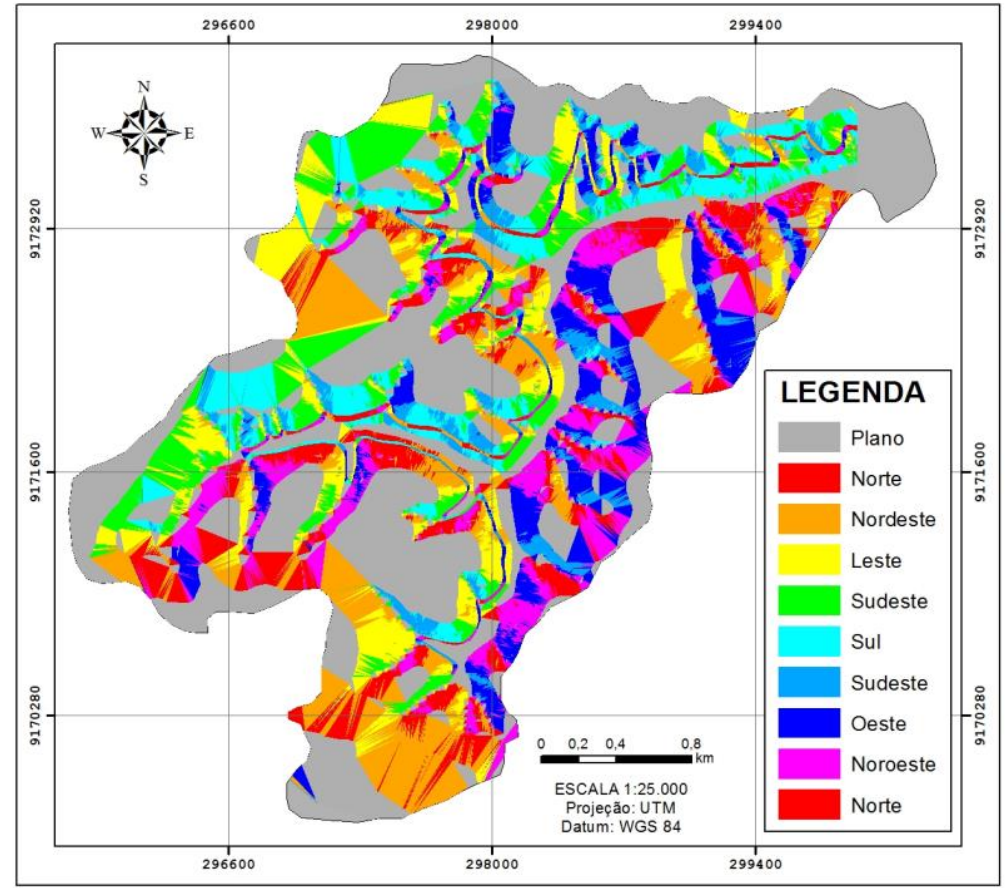

Figura 5. Mapa de exposição de vertentes da bacia do riacho Engenho Velho, Pitimbu (PB). 


\section{CONSIDERAÇÕES FINAIS}

A aplicação de técnicas de geoprocessamento através de variáveis geomorfométricas para a identificação e mapeamento de solos na bacia do riacho Engenho Velho se mostrou bastante eficiente na orientação de estratégias para trabalhos de campo que serão realizados, em meio as variações da paisagem. Através das observações foi possível verificar que os fenômenos naturais ocorrentes na referida área de estudo, tais como elevação, exposição das vertentes e o grau de inclinação estão influenciado de forma relevante nos processos de formação e evolução dos solos ocorrentes na área.

\section{REFERÊNCIAS}

ANSELMO, M. G. V. Caracterização e classificação de Argissolos na reserva legal riacho Pacaré, Rio Tinto - PB. Monografia (Licenciatura em Geografia) - Universidade Estadual da Paraíba, Guarabira, Paraíba, 2011.

BARBOSA, I. S.; ANDRADE, L. A.; ALMEIDA, J. A. P. Zoneamento agroecológico do município de Lagoa Seca, PB. Revista Brasileira de Engenharia Agrícola e Ambiental, v. 13, n. 5, p.623632, 2009.

BARBOSA, J. A.; LIMA FILHO, M. Os domínios da bacia da Paraíba. In: $3^{\circ}$ Congresso Brasileiro de P\&D em Petróleo e Gás. 2004. Salvador: Instituto Brasileiro de Petróleo e gás. 2005.

BARROS, Z. X.; TORNERO, M. T.; STIPP, N. A. F.; CARDOSO, L. G.; POLLO, R. A. Estudo da adequação do uso do solo, no município de Maringá - PR, Utilizando-se de geoprocessamento. Eng. Agríc. Jaboticabal, v.24, n.2, p.436-444. 2004.

BELTRÃO, B. A.; MORAIS, F.; MASCARENHAS, J. C.; MIRANDA, J. L. F.; JUNIOR, L. C. S.; MENDES, V. A. Projeto cadastro de fontes de abastecimento por água subterrânea. Diagnóstico do município de Pitimbu, estado da Paraíba. CPRM - Serviço Geológico do Brasil. 11p. 2005.

BRAGA, E. L.; LEITE, F. A. B.; MOTA, F. O. B.; LEITE, F. R. B.; CHAVES, L. C. G.; BARRETO, M. M. S.; NETO, M. B. O.; BARRETO, R. N. C.; CUNHA, S. F.; OLIVEIRA, S. B. P. Mapeamento de Solos Utilizando Técnicas de Geoprocessamento. In: Simpósio Brasileiro de Sensoriamento Remoto.2009, Natal. Anais XIV. Natal: INPE, 2009. p. 3605-3611.

CALDERANO FILHO, B.; CHAGAS, C. S.; PRADO, R. B.; PEREZ, D. V.; BENITES, V. M.; FREITAS, P. L.; GONÇALVES, A. O.; SILVA, J. S. Levantamento Semidetalhado dos Solos da Microbacia do Barro Branco, Município de São José do Ubá, Estado do Rio de Janeiro. Embrapa Solos. VIII. Título. IX. Série. Dezembro de 2005.

CAMPOS, M. C. C.; CARDOSO, N. P.; JÚNIOR, J. M. Modelos de Paisagem e sua Utilização em Levantamentos Pedológicos. Revista de Biologia e Ciências da Terra. v. 6, n. 1, p. 104-114. 2006. 
CAMPOS, M. C. C.; QUEIROZ, S. B. Reclassificação dos perfis descritos no levantamento exploratório-reconhecimento de solos do estado da Paraíba. Revista de Biologia e Ciencias da Terra, v. 6, n. 001, p. 45-50, 2006.

CARVALHO JÚNIOR, W. C; CHAGAS, C. S.; PEREIRA, N. R.; STRAUCH, J. M. C. Elaboração de zoneamentos agropedoclimáticos por geoprocessamento: soja em municípios do Rio Grande do Sul. Revista Brasileira de Ciência do Solo. p. 381-389. 2003.

CARVALHO, C. C. N.; ROCHA, W. F.; UCHA, J. M. Mapa digital de solos: Uma proposta metodológica usando inferência fuzzy. Revista Brasileira de Engenharia Agrícola e Ambiental, v.13, n.1, p.46-55, 2009.

COELHO, F. F. Comparação de métodos de mapeamento digital de solos através de variáveis geomorfométricas e sistemas de informações geográficas. 2010. 95 p. Dissertação (Mestrado Sensoriamento Remoto) - Universidade Federal do Rio Grande do Sul, Porto Alegre, 2010.

COSTA, A. M.; CURI, M.; MENEZES, M. D.; ARAÚJO, E. F.; MARQUES, J. J. Levantamento detalhado de solos da microbacia hidrográfica do Horto Florestal Terra Dura (RS) e considerações sobre escalas de mapeamento. Ciênc. agrotec., Lavras, v. 33, n. 5, p. 1272-1279, set./out., 2009.

DIAS, L. M. S.; COELHO, R. M.; OLIVEIRA, S. R. M.; BARROS, F. M. M. Mapeamento pedológico digital com base no relevo e treinamento por amostragem de solos desenvolvidos de arenitos. Revista Equador (UFPI), v. 4, n. 4, p.36-44, Jul./Dez., 2005.

DINIZ, M. T. M.; ALMEIDA, I. C. S.; SILVA, S. D. R.; PEREIRA, E. M. Pedologia e análise da paisagem: Interações ambientais em Junco do Seridó/PB. Caderno Prudentino de Geografia, Presidente Prudente, n.35, v.1, p.90-111, 2013.

DUARTE, S. M. A.; SILVA, I. F.; MEDEIROS, B. G. S.; ALENCAR, M. L. S. Levantamento de solo e declividade da microbacia hidrográfica Timbaúba no Brejo do Paraibano, através de técnicas de fotointerpretação e sistema de informações geográficas. Revista de biologia e ciências da terra, v. 4, n. 2, 2004.

FIORIO, P. R.; DEMATTÊ, J. A.; SPAROVEK, G. Cronologia e impacto ambiental do uso da terra na bacia hidrográfica do Ceveiro, em Piracicaba, SP. Pesquisa Agropecuária Brasileira. v. 35, n. 4, 2000, p 671-679.

FRANCISCO, P. R. M.; SANTOS, D.; LIMA, E. R. V. Mapeamento pedológico das terras no estado da Paraíba utilizando sistema de informação geográfica. Congresso Técnico Científico da Engenharia e da Agronomia, 2015.

FURRIER, M. Caracterização geomorfológica e do meio físico da carta de João Pessoa - 1: 100.000. Tese (Doutorado em Geografia) - Universidade de São Paulo, São Paulo, São Paulo, 2007.

IPPOLITI R, G. A.; COSTA, L. M.; SCHAEFER, C. E. G. R.; FILHO, E. I. F.; GAGGERO, M. R. Análise digital do terreno: ferramenta na Identificação de pedoformas em microbacia na região de “mar de morros" (MG). Revista Brasileira de Ciência do Solo, p. 269-276. 2005.

JACOMINE, P. K. T. A nova classificação brasileira de solos. Anais da Academia Pernambucana de Ciência agronômica, Recife, v. 5 e 6, 2008-2009, p. 161-179. 
LACERDA, M. P. C.; BARBOSA, I. O.; MENESES, P. R.; ROSA, J. W. C.; ROIG, H. L. Aplicação de geotecnologias em correlações entre solos, geomofologia, geologia e vegetação nativa no Distrito Federal, DF. In: Simpósio Brasileiro de Sensoriamento Remoto, Goiânia, Brasil. 2005, Goiânia. Anais XII: Goiânia INPE, 2005. p. 2211-2218.

LACERDA, M. P. C.; SOUZA, R. Q.; VIEIRA, B. G.; JÚNIOR, M. P. O. Modelo de distribuição de solos na Microbacia do Ribeirão Salinas, Distrito Federal. In: Simpósio Brasileiro de Sensoriamento Remoto - SBSR, 20015, João Pessoa. Anais XVII: Paraíba: INPE, 2015. p. 12631269.

LEPSCH, I. F. As necessidades de efetuarmos levantamentos pedológicos detalhados no Brasil e de estabelecermos as séries de solos. Revista Tamoios, n. 1, p. 3-15. 2013.

MENDOÇA, I. F. C.; LOMBARDI NETO, F.; VIÉGAS, R. A. Classificação da capacidade do uso das terras da Microbacia do Riacho Una, Sapé, PB. Revista Brasileira de Engenharia Agrícola e Ambiental, v. 10, n. 4, p. 888-895, 2006.

MENDONÇA-SANTOS, M. L.; SANTOS, H. G. Mapeamento digital de classes e atributos de solos: métodos, paradigmas e novas técnicas. n. 55, Rio de Janeiro, Embrapa solos, 2003.

MOURA, G. F. A pesca do camarão marinho (Decapoda, Penaeidae) e seus aspectos sócioecológicos no litoral de Pitimbu, Paraíba, Brasil. 134 p. Tese (Doutorado em Oceanografia) Universidade Federal de Pernambuco, Recife, 2005.

NASCIMENTO, S. S.; LIMA, E. R. V.; MACÊDO, M. L. A.; LIMA, P. P. S.; RÊGO, S. C. A. Mapeamento do uso e adequação do solo no município de São Domingos do Cariri-PB. In: Simpósio Brasileiro de Sensoriamento Remoto - SBSR. 2011, Foz do Iguaçu-PR, Anais XVI. Foz do Iguaçu-PR: INPE, 2013. p. 4840-4847.

PEREIRA, M. S.; ALVES, R. R. N. Composição Florística de um remanescente de Mata Atlântica na Área de Proteção Ambiental Barra do Rio Mamanguape, Paraíba, Brasil. Revista de biologia e ciências da terra. v. 7, n. 1, p. 1-10. 2007.

ROSSI, M.; QUEIROZ NETO, J. P. Relações solo/paisagem em regiões tropicais húmidas: O exemplo da Serra do Mar em São Paulo, Brasil. Revista do departamento de geografia. p. 11-23. 2001.

SARMENTO, E. C.; FLORES, C. A.; WEBER, E; HASENACK, H.; PÖTTER, R. O. Sistema de informação geográfica como apoio ao levantamento detalhado de solos do Vale dos Vinhedos. Revista Brasileira de Ciência do Solo. Número especial, p. 2795-2803. 2008.

SILVA, T. G.; TOMAZONI, J. C.; GUIMARÃES, E.; GOMES, T. C. Utilização de álgebra de mapas para caracterização dos solos da bacia hidrográfica do rio Catorze. In: Simpósio Brasileiro de Sensoriamento Remoto - SBSR. 2011, Curitiba, Anais XV, Curitiba-PR: INPE, 2011. p.4840-4047.

SILVEIRA, C. T. Análise digital do relevo na predição de unidades preliminares de mapeamento de solos: integração de atributos topográficos em sistemas de informações geográficas e redes neurais artificiais. 154 p. Tese (Doutorado em Geografia) - Universidade Federal do Paraná, Curitiba, 2010. 
SOUSA, R. F.; BARBOSA, M. P.; JÚNIOR, S. P. S; NETO, C. P. C. T.; LIMA, A. N. Solos e classes de terras para irrigação no município de Itaporanga, PB. Revista Caatinga, v. 20, n. 4, p. 116-122, 2007.

SOUSA, R. F.; MOTTA, J. D.; GONZAGA, E. N.; FERNANDES, M. F.; SANTOS, M. J. Aptidão agrícola do assentamento Venâncio Tomé de Araújo para a cultura da Mamona (Ricinus communis - L.). Revista de Biologia e Ciência da Terra, v. 4, n. 1, 2004.

TEOTIA, H. S.; SILVA, I. F.; SANTOS, J. R.; JUNIOR, J. F. V.; GONÇALVES, J. L. G. Classificação da cobertura vegetal e capacidade de uso da Terra na região do Cariri Velho (Paraíba), através de Sensoriamento remoto e geoprocessamento. Anais XI SBSR, Belo Horizonte, Brasil, 05, p. $1969-1976,2003$.

Recebido em: 14/08/2016

Aceito para publicação em: 01/10/2016 